BY VINCENT CARRET*

\begin{abstract}
Ragnar Frisch's famous "rocking horse" model has been the object of much praise and even controversy since its publication in 1933. This paper offers a new simulation of the model to show that there exists cyclical trajectories in the propagation mechanism. By building an analytical solution taking the same form as Frisch's original solution, we can provide new insights into the ideas encapsulated in his model, in particular the fact that the author constructed a model combining cycles and growth. The exploration of Frisch's formal construction of the model leads us to link his statistical work on the decomposition of time series with his economic insights on investment cycles, which both led to the 1933 model. We contrast Frisch's approach to that of other econometricians who used similar equations, showing that their different mathematical solutions were the product of what they wanted to show with their models.
\end{abstract}

* Université Lyon II - Triangle. Contact: vincent.carret@univ-lyon2.fr

This "preprint" is the peer-reviewed and accepted typescript of an article that is forthcoming in revised form, after minor editorial changes, in the Journal of the History of Economic Thought (ISSN: 1053-8372), issue TBA. Copyright to the journal's articles is held by the History of Economics Society (HES), whose exclusive licensee and publisher for the journal is Cambridge University Press.

(https://www.cambridge.org/core/journals/journal-of-the-history-of-economic-thought) This preprint may be used only for private research and study and is not to be distributed further.

The preprint may be cited as follows:

Carret, Vincent. Fluctuations and growth in Ragnar Frisch's rocking horse model. Journal of the History of Economic Thought (forthcoming). Preprint at SocArXiv, osf.io/preprints/socarxiv 


\title{
Fluctuations and growth in Ragnar Frisch's rocking horse model
}

\author{
Vincent Carret
}

\section{INTRODUCTION}

In 1969, Ragnar Frisch received the first "Nobel Prize" in economics (shared with Jan Tinbergen), "for having developed and applied dynamic models for the analysis of economic processes." ${ }^{1}$ One of his pioneering contributions in this respect was his 1933 article "Propagation Problems and Impulse Problems in Dynamic Economics" (Frisch 1933). Today, this article is still remembered and celebrated for his approach to macroeconomic phenomena, especially by the New Classicals who have regularly insisted on the necessity to find propagation mechanisms and to differentiate them from the impulses (see for instance the references to Frisch in Robert Lucas and Thomas Sargent [1979] or Edward Prescott [2006]). ${ }^{2}$ The idea of separating a propagation mechanism, explaining the form of the return to equilibrium, and an impulse mechanism, explaining the persistence of business cycles when the propagation is in the form of a damped cycle, has been one of the most enduring contributions of Frisch's article and his work.

How did Frisch come to this idea in 1933? His debate with John M. Clark in the Journal of Political Economy in 1931-1933 has been underlined as one of the main impetus to write this

1 See the "facts" page for Frisch on the website of the Nobel Prize (https://www.nobelprize.org/ prizes/economic-sciences/1969/frisch/facts/, consulted in september 2020).

2 On the definition of shocks by Frisch, and the role he played in establishing a modern understanding of them, see Duarte and Kevin Hoover (2012), who examined how the notion of shocks was transformed after Frisch, and "rediscovered" by the New Classicals. Muriel Dal Pont Legrand and Harald Hagemann (2019) argued that the role of propagation mechanisms progressively lost importance after the war. 
article and clarify the importance of a determinate system. ${ }^{3}$ Another important source of inspiration was his correspondence with Joseph Schumpeter and the role of the pendulum metaphor, which has been particularly discussed by Franscisco Louçã (2001), who used an original correspondence between the two economists to show their different opinions on the validity of the metaphor. The influence of other Scandinavian economists on Frisch, and particularly the Swedish school, has also been the subject of several detailed studies, for instance from Mauro Boianovsky and Hans-Michael Trautwein (2007), who showed that Frisch introduced his distinction between impulse and propagation in part as an answer to a debate with Johan Åkerman, sparked by the defense of the latter's PhD thesis in 1928, where Frisch was present. Dupont-Kieffer (2003, 2012a) underlined the importance of the collection of statistics and national accounts, in particular in connection with Erik Lindahl's work at the same time. And Frisch attributed to Knut Wicksell the image of a rocking horse periodically hit that he used to illustrate the combination of impulses and propagation. The influence of the soviet statisticians and mathematicians was also important: Eugen Slutzky presented in particular the idea that regularities could arise from the apparently random "chaos of disconnected elements" (Slutzky 1937, p. 106), an idea which inspired Frisch's own approach to shocks. ${ }^{4}$ Finally, one of the most important sources of inspiration of Frisch was his own methodological approach to modelbuilding, which found a fertile ground in a small, but growing group of economists who gathered to create the Econometric Society and the new field of econometrics. The Society fostered important discussions from its first European meeting in Lausanne, where Jan Tinbergen presented several models based on differential-difference equations, which were then used by

3 On the origins of Frisch's model and for a detailed analysis of the hypotheses of his model, see Ariane Dupont-Kieffer (2012b). Olav Bjerkholt (2007) lists many of the influences of Frisch during the end of the 1920s and early 1930s. On Frisch himself, particularly during the interwar period, see the works of Jens C. Andvig (1981); Bjerkholt (1995); Bjerkholt and Dupont-Kieffer (2010). Dupont-Kieffer (2003) showed in particular in her thesis the opposition of approaches between Frisch and Wesley C. Mitchell.

4 Slutzky originally published his paper in Russian in 1927 and it was translated in English ten years later in Econometrica (Slutzky 1937). Vincent Barnett (2006) has discussed two interpretations of Slutzky's ideas: the "real" and the "spurious": in the former, the summation of random events giving rise to cycles is considered a significant mechanism that can be economically interpreted, while the latter interpretation only notes that spurious cycle can arise from the simplest statistical manipulations of empirical data. By describing the original context of Slutzky's research at the Moscow Conjuncture Institute and the importance of the diffusion of harmonic analysis on the development of his ideas, Marco Vianna Franco et al. (2021) have defended the idea that Slutzky viewed his contribution in relation to what became the first interpretation. 
both Frisch and Michał Kalecki in the models they presented in another Econometric Society meeting, two years later in Leiden. ${ }^{5}$

This article traces the evolution of Frisch from his ideas on investment and the analysis of time series in the late 1920s, to his model published in 1933. While the complete model is made up of the propagation mechanism plus the random shocks that hit this mechanism, we are concerned here by the propagation mechanism only. It is important to highlight that it was the concept of impulses hitting a system that was particularly retained from Frisch's contribution, an idea which was subsequently applied to other models with different propagation mechanisms. Nonetheless, Frisch's own propagation mechanism is interesting in its own right: it is based on a mixed differential-difference equation, and this was influenced by his particular approach to harmonic analysis and his early program of statistical exploration. The solution to Frisch's model is made of a sum of components, which allowed him to represent both cycles and growth in his model. But such a mathematical approach would have been fruitless if it had not been supported by an economic theory, and it was his search of the sources of investment fluctuations and their relation to consumption changes that allowed him to present a truly economic model based on a new mathematical formalism. Exploring this formalism is not a vain effort: it allows us to show that there are truly cyclical solutions arising from the propagation mechanism for small changes in the original parameters, and that there was in Frisch's model the willingness to represent both growth and fluctuations, something which was not widely adopted later on in other macrodynamic models.

The evolution of Frisch's statistical methodology into a mathematical approach happened in parallel with the discussions he had with other economists about problems in investment theory, which led him to formulate the equations of his 1933 model (section II). It is possible to solve this model with an analytic solution which takes a similar form than his original solution and does not change the model, although it is based on modern mathematical tools that he did not

5 See Mary Morgan (1990) and Louçã (2007) for detailed studies of how econometric ideas came into existence and spread among economists, and Philippe Le Gall (1993), who compared the models of Frisch and Kalecki. The ideas presented by the first econometricians, in particular those related to macrodynamics and stability, are detailed in a forthcoming book (Assous and Carret 2021), which goes back on the different visions of the world encapsulated in the models built in the 1930s and 1940s by Ludwig Hamburger, Tinbergen and others in Europe, as well as Samuelson and Oskar Lange in the United States. 
know. This makes more apparent the presence of a "secular trend" that was in the original paper, where Frisch presented a model of fluctuations and long-term growth (section III). The fact that the properties of his model, and in particular the presence of a secular trend in addition to fluctuations, are a characteristic of his mathematical approach is discussed in the subsequent section. Frisch was not alone in working with mixed differential-difference equations, and the lack of proper tools to solve them meant that he and others developed very different approaches to deal with their solutions; these approaches were driven by their relevance to the authors' economic aims (section IV). Finally, we discuss the use and limits of modern tools to understand the work of authors who did not have them at their disposal; our conclusion is that computer simulations can be valuable when they are used to reconstruct the process of thought and the obstacles faced by an author rather than his model (section V).

\section{HARMONIC DECOMPOSITION AND INVESTMENT FLUCTUATIONS}

The 1920s saw a marked increase in the empirical study of business cycles, which was driven by the development of several methodologies dealing with the explosion in availability of economic data. One of these approaches was based on the idea that business cycles could be disaggregated into several component cycles and that it was possible to analyze the structure of lags, relative importance and frequencies of those components to make predictions on the future phase of the business cycle. This idea stemmed largely from the discovery during the second part of the 19th century of cycles of different lengths, and it was built upon and applied in particular by Warren Persons, who established the famous tool of the "economic barometer" and the ABC curves. ${ }^{6}$

Persons' method relied on the elimination of seasonal variation and trend, and the computations of correlations between time series. This was a source of inspiration for Frisch in the early 1930s, as he referred to it in his Yale lectures, given in October 1930 while he was in

\footnotetext{
6 See in particular chapter 2 of Morgan (1990) on the developments of the empirical approach to the business cycle.
} 
the United States. ${ }^{7}$ According to Frisch, the "general theory" presented by Cournot and Persons distinguished the erratic, seasonal, and cyclical fluctuations and the trend. But this division was not enough for him, and he argued that it was necessary to break up into many components the cyclical fluctuations (Bjerkholt and Qin 2010, p. 15).

The approach of finding many components in a time series was defended in the 1920 s most notably by Henry L. Moore. ${ }^{8}$ To decompose a time series, he relied on the periodogram, a tool developed in the physical sciences which he was most responsible for importing in economics. ${ }^{9}$ The techniques employed date back from the groundbreaking work of Joseph Fourier (1822), who explained, in the context of the diffusion of heat, how almost any curve could be synthesized as the sum of simple periodic curves (sinusoidal curves). One of the multiple tools that was born out of what became known as "Fourier analysis" was the periodogram, that became used to identify in a time series which particular frequencies were most important, that is, which component cycles (sinusoids) of a Fourier decomposition of a time series had the most energy (the largest amplitude).

Frisch worked on this idea in the late 1920s, and tried to devise a new method to compute the coefficients of components with amplitude and period varying in time (Frisch 1928). ${ }^{10}$ Frisch illustrated his problem with a chain of pendula: if we have the information on the movement of the last pendulum of the chain, and the lengths of each pendulum, we can obtain the movements of each intermediate pendulum in the chain with a harmonic decomposition of the movement observed at the end of the chain. However if the lengths of the pendula or the intensity of the

7 Although the text of this particular lecture did not seem to have survived, a trace remains in the students notes that have been conserved in his archives (see the editors' introduction to the lectures, Bjerkholt and Qin [2010]).

8 For instance in Moore (1921), where the problem is presented very pedagogically; Moore was against detrending his data and also proposed to integrate a "secular trend," which was represented as another component of the Fourier decomposition with a multisecular period (Moore 1921, p. 509).

9 On the development of spectral methods see in particular Harold Davis (1941, chapter 1), and Thomas Cargill (1974). On the transfer of the periodogram from physics to economics by Moore, see also Le Gall (1999). Morgan (1990, chapter 1) presented Moore's ideas on this subject, but was more preoccupied with the Venus cycle and did not notice his treatment of the secular trend. For a recent evaluation of Moore's work and his approach to periodogram analysis, see Paul Turner and Justine Wood (2020), who argue that Moore's often derided argument that the business cycle was driven by the movements of Venus should not hide the originality of his approach.

10 Morgan (1990, pp.83-90) has given one of the most thorough discussions of Frisch's work in time series analysis. See also Bjerkholt (2007) for a review of the publications and communications of Frisch during this period. Boianovsky and Trautwein (2007) also discussed the competing views of Frisch and Åkerman on the decomposition of statistical time series. 
gravitational field are changing over time, a Fourier decomposition of the movement will not be able to correctly decompose the intermediate movements because it supposes that parameters are held constant. If his pendula were damped, as they are in the physical world, it would mean that the solution of his decomposition would involve a sum of damped sinusoids changing over time, a rather complex system. His ideas on this subject, while acknowledged by Davis (1941) in his introductory chapter on the history of the analysis of time series, did not have an important impact on the development of spectral analysis, in large part because other advances were made at the same time. ${ }^{11}$ Morgan also argued convincingly that it was abandoned because it could not represent in any way the relationships between the variables, something that Frisch was very much conscious of (Morgan 1990, p. 90).

The identification of those relationships formed another part of Frisch's program of empirical exploration that we can find laid out for instance in his communication at the 1930 meeting of the American Statistical Association (Frisch 1931a). In this paper, Frisch identified four groups of problems in the analysis of time series: their decomposition (the subject of his communication and of his previous work published in 1928), the comparison of different time series, the forecasting problem, and the "explanation problem":

When we have found that a given series contains certain components, we ask the further question: How did these things come into the series? In a sense, this is the crucial question of time series analysis. ... But answering such a question means working out a whole rational explanation of the phenomenon at hand. This is not a question of time series technique any more, but a question of the whole content of the theory of the particular phenomenon at hand. (Frisch 1931a, p. 74)

This quote underlines the fact that the statistical exploration of time series and the increasingly complex schemes developed by Frisch to decompose them were only one side of his analysis of business cycles. Another side, answering the "explanation problem," seems to have been increasingly on the mind of the Norwegian economist at the turn of the decade, when he tried to explain economic fluctuations based on the relationship between investment, reinvestment and consumption.

11 Norbert Wiener in particular was the foremost authority on Fourier analysis at the time, and his 1930 study (Wiener 1930) was cited by Frisch in 1933 (Frisch 1933, p. 29). Incidentally, Wiener was present at the inaugural meeting of the Econometric Society in Cleveland although he did not get involved in the society afterward. 
Frisch's forays into capital theory and the problem of economic fluctuations had begun as soon as 1927, in a paper published in the Statsøkonomisk Tidsskrift. ${ }^{12}$ This paper was written after a certain Dr. Shoenheyder had asked Frisch to give a mathematical formulation of his theory of crisis, and although Frisch was not really interested in such an undertaking, he was interested in the connection between "a given primary investment and the reinvestment that is necessary to maintain the specific capital objects created by the given primary investment" (Frisch 1927, p. 117). In this paper, Frisch gave several examples of an investment in capital goods with different durabilities, for instance three hammers, one in wood, one in iron, and one in steel with respective durabilities of one, two and three years. He then showed that the pattern of reinvestments arising from this initial investment gave rise to visible fluctuations; but for him there was little economic interpretation possible of this example, because those fluctuations were mainly a mathematical artifact disappearing when the analysis was made continuous. ${ }^{13}$ However, there was another case of fluctuations to which an economic significance could be attributed, arising from a non-uniform distribution of the initial capital (Frisch 1927, pp. 118-119), which he subsequently explored as well as the damping out of those fluctuations.

As has been argued by John Chipman (1998), there are at least two influences of this early approach of reinvestment cycles on Frisch's ulterior work in capital theory: the first is that Frisch continued to be interested in problems of reinvestment, which became the core of his equation for investment in the 1933 model. The second is that he showed in the rest of the 1927 paper that the fluctuations in reinvestment would be damped in more general cases, and that they would converge to a steady value of necessary reinvestment to maintain a certain level of capital.

The link between his rocking horse model and the earlier paper on reinvestment cycles was made through the debate with John M. Clark in the Journal of Political Economy. ${ }^{14}$ This debate began when Frisch visited Alvin Hansen at the University of Minnesota, at the end of a stay in the United States; their discussions concerned the role of the accelerator, used in particular by

12 We thank an anonymous referee for pointing out this article as a forerunner of Frisch's 1933 model.

13 "The question is what economic significance one should attach to this fluctuation. In section 2, I will seek to show that the fluctuation in the annual reinvestment that appears in this example cannot be attributed any economic significance." (Frisch 1927, p. 118)

14 The link between the 1927 paper and Frisch's model was developed by Dupont-Kieffer (2012b, p. 453), who also went back on the connection between the two through the Clark-Frisch debate. 
Hansen and Clark to explain economic fluctuations, but Frisch argued that Clark and other "literary" economists did not see that their models were not determinate, and lacked in particular a relation to explain the level of consumption.

To show clearly the problem, Frisch sought to build a small model that would clarify what was wrong with the empirical and literary analysis of the interaction between investment and consumption. In this simple model, the capital production $w$ was a function of consumption $z$ and its rate of change $\dot{z}$ such that $w=k(h \cdot z+\dot{z})$, where $k$ is the constant proportionality between consumption and the capital stock and $h$ the depreciation rate of the latter. The increase in capital production is then $\dot{w}=k(h \cdot \dot{z}+\ddot{z})$, which means that new investment depended on both the increase of consumption and the rate of change of this increase (quite literally, its acceleration):

Thus there are two forces that act upon total capital production. If consumer-taking is increasing, but at a constantly decreasing rate, the first of these two forces tends to increase, and the second tends to slow down capital production. Which one of the two forces shall have the upper hand depends on the manner in which the increase in consumer-taking slows down, and it depends also on the rate of depreciation." (Frisch 1931b, p. 648).

Hence a part of investment came from replacement needs, while another stemmed from the expansion needs arising from an increase in consumption. If the replacement needs were more important than those arising from consumption, there would not be any turning point, only a gradual approach to an equilibrium, in which case investment could not fluctuate. But Frisch criticized the fact that this simple system left unexplained the trajectory of consumption: the model was not mathematically determinate. In his answers, Clark suggested several possibilities to close the model, in particular with an equation relating purchasing power and total production (Clark 1932, p. 692). But Frisch did not use this idea and instead proposed in 1933 to close the model with an equation determining the "encaisse désirée," to obtain a system of "free oscillations," where external shocks revived the damped cycles.

Thus Frisch's 1933 paper provided an answer to the "explanation problem." The pendula metaphor gives an insight into the deeper link between his earlier statistical work and his new macrodynamic work, beyond the fact that they were both different sides in the analysis of time 
series. In 1928, the pendula were used to illustrate his process of decomposition, as a simplification of a time series. What the 1933 paper amounted to was to find the equations of motion of the system of pendula, rather than taking as a given the trajectory of the last one of the chain. The link is explicit in the article, where Frisch described the motion of his perturbed pendulum by the term "changing harmonic," which was the title and subject of the 1928 article. His description had not changed although it applied to a formal model: "By a changing harmonic I understand a curve that is moving more or less regularly in cycles, the length of the period and also the amplitude being to some extent variable" (Frisch 1933, p. 32). This continuity can also be seen if we look at the formal structure of the model built in 1933, and compare it to the way in which Frisch suggested to decompose time series: it is a striking feature of his 1933 model that the solution can be expressed as a sum of components, that can take the form of sinusoids (cycles) or trends, in the same way that the harmonic decomposition of a time series will be a sum of sinusoids with different amplitudes.

In its final form, the model was made up of three equations. The accelerator relationship of the 1931 paper was present in the slightly different form:

$$
y(t)=m \cdot x(t)+\mu \cdot \dot{x}(t)
$$

Where $y(t)$ is the investment and $x(t)$ is the consumption at time $t, m$ is a constant coefficient for the total depreciation of the capital stock, and $\mu$ a constant for the sensitivity of changes in investment needed to accommodate changes in consumption.

To close the model by explaining changes in consumption, Frisch introduced the idea of "encaisse désirée," taken from Walras although he discarded any links with a monetary theory of the business cycle (Frisch 1933, p. 9). ${ }^{15}$ The encaisse désirée is equal to the cash needed for the exchange of consumer and producer goods, a proportion $\omega=r x+s y$ of the volume produced of each goods, which increased during the expansion phase of the cycle. Frisch used this equation as a stabilizing mechanism, remarking that the monetary stock cannot expand infinitely, and that

15 The essential mechanism in Frisch's model was indeed the accelerator, and as such his approach to business cycles could be classified as a "real" approach as opposed to the "monetary" approach defended at the time by Friedrich Hayek and many other business cycle theorists. 
the resulting tension during the boom will restrict consumption, "one of the elastic factors in the situation" (Frisch 1933, p. 9). This led to an equation for the rate of increase in consumption:

$$
\dot{x}(t)=c-\lambda(r \cdot x(t)+s \cdot y(t))
$$

Where $c$ is a fixed level of consumption increase, and $\lambda, r$ and $s$ are constant parameters. But this model yielded a first-order non-homogeneous linear differential equation, which could only give rise to exponential solutions and never to oscillations. To allow for the possibility of fluctuations, Frisch introduced a third equation for the "carry-on activity," $z(t)$, that is, the current production of investment and consumption goods, which depends on the production started during the last interval of time $\epsilon:^{16}$

$$
z(t)=\frac{1}{\epsilon} \int_{t-\epsilon}^{t} y(\tau) d \tau
$$

The production $z(t)$ was then substituted in the equation for the changes in consumption, such that the changes in consumption depended on the level of activity rather than the past decisions of investment.

$$
\dot{x}_{t}=c-\lambda(r \cdot x(t)+s \cdot z(t))
$$

By explaining the level of production with a lag, Frisch created a model mixing differential and difference equations, which was able to give rise to all sorts of movements, and whose solution was made up of an infinity of components. This feature was known to Frisch because Tinbergen had already started to study those equations in the early 1930s, and had presented his preliminary results during the 1931 Lausanne meeting of the Econometric Society (Tinbergen 1933). Thus one is led to conclude that Frisch selected this specific form for his model at least in part because he knew that he would obtain a solution made of a sum of components.

16 Frisch's notation of $z(t)$ is rather confusing. This form makes it clear that we want the integral of y over the interval $t-\varepsilon$ to $t$, and computations give the same results as Frisch. 


\section{THE "SECULAR TREND" AND THE POSSIBILITY OF GROWTH IN THE ROCKING HORSE MODEL}

To solve his model, Frisch did not have a lot of possibilities available. The theory of delay differential equations (DDEs), as the mixed type of equations is usually called today, was not even begun, and the behaviour of such equations is often much more complex than that of ordinary differential equations or difference equations. ${ }^{17}$ Frisch remarked that the solution of his equation could be expressed as a sum of exponentials, which is one way to express a Fourier series. ${ }^{18}$ In the case of the latter the arguments of the exponentials will be complex numbers with a multiple of two in the imaginary part and a real part equal to zero, so that every component of the series is cyclical and has a constant amplitude. Frisch did not assume such restrictions on the inputs of the exponential functions of his series, which meant that they could very well be real numbers, yielding a monotonous trajectory, or complex numbers with a nonzero real part, generating either a damped (real part inferior to zero), or explosive (real part superior to zero) trajectory.

To find a solution, Frisch still had to obtain from the parameters of the model and a set of initial conditions the frequencies and damping of the components of the infinite series, as well as their coefficients (the latter being the customary part of Fourier analysis). It is on this point that we can give a more elegant answer than Frisch's to the computation of the components, while respecting his original process of finding a solution made of a sum of damped sinusoids. This is possible because of the work done by Richard Bellman, Kenneth Cooke and other applied mathematicians during the 1940s and 1950s, which resulted in the publication by Bellman and Cooke of an important monograph on DDEs in 1963 (Bellman and Cooke 1963). It should also be noted that this is the logical extension of Frisch's approach to the problem, as Bellman and

17 In fact DDEs belong to a special class of functional differential equations and are closer to partial differential equations (PDE), than to ordinary differential equations. It is not a coincidence that Fourier analysis and its offshoots were developed to solve PDEs and are well-suited for DDEs.

18 Chipman (1998, p. 93) argued that this approach was rooted in Lotka's solution of the renewal equation, but the debates around this equation seem to be subsequent to Frisch's work on the problem; Bellman and Cooke (1963), in their study of differential-difference equations, did however spend a chapter on the renewal equation so that there may be an interesting connection to draw, which is beyond the scope of this paper. 
Cooke referred explicitly to the work of the economists working during the interwar on mixed equations (see the next section).

While Bellman and Cooke developed several approaches to deal with DDEs, one in particular allows us to retrieve the same infinite sum that Frisch used in his article: the Laplace transform and its inversion. This transform is close to the Fourier transform, but more adapted for the study of differential-difference equations. In particular, once applied to this type of equations, it will give an infinite sum of components that can be expressed as a function of the parameters of the system, the roots of a characteristic equation, and the initial conditions determined by the model-builder.

To apply the Laplace transform to Frisch's system of three equations (1), (2) and (3), we start by reducing it by substitutions to one integro-differential equation with one unknown variable, the consumption $x$. Doing this, we obtain the following integro-differential equation with a lag in the state variable and the integral: ${ }^{19}$

$$
\dot{x}(t)+\lambda\left(r+\frac{s \mu}{\epsilon}\right) x(t)-\frac{\lambda s \mu}{\epsilon} x(t-\epsilon)+\frac{\lambda s m}{\epsilon} \int_{t-\epsilon}^{t} x(\tau) d \tau=c
$$

Applying to this equation the Laplace transform and its inverse, we obtain the following solution for $x$, a sum of components similar to the one in Frisch (1933): ${ }^{20}$

$$
x(t)=\overbrace{\frac{c}{\lambda(r+s m)}}^{(i)}+\overbrace{k_{1} e^{r_{1}(t-\epsilon)}}^{(i i)}+\overbrace{\sum_{i=2}^{\infty} A_{i} e^{\alpha_{i}(t-\epsilon)} \cos \left(\beta_{i}(t-\epsilon)+\phi_{i}\right)}^{(i i i)}
$$

There are three distinct terms on the right hand side of this equation. (i) On the left, an equilibrium level, determined as a function only of the parameters of the system. (ii) In the

19 This equation can also be found in a differentiated form in Zambelli (1992, p. 32), and Boumans (1999, p. 80).

20 See Chapter 1 in Bellman and Cooke (1963) for a discussion of the inversion algorithm, and Chapter 3, section 7 for a detailed application to a simpler equation. Note that the expression (5) is defined for $t \geq \varepsilon$, and that the evolution of $\mathrm{x}$ for $0 \leq \mathrm{t}<\varepsilon$ is supplied as an initial condition. 
middle, we find an exponential function with a real argument, that will be stable or unstable according to the parameters of the system (which determine the first root $r_{1}$ ), and that was dubbed by Frisch a "secular trend" because it generated a monotonous trajectory. (iii) On the right, there is an infinite sum of sinusoidal solutions, each with its own frequency $\beta_{i}$ and damping exponent $\alpha_{i}$ (so that $r_{i}=\alpha_{i}+j \beta_{i}$ for $i>1$ with $j=\sqrt{-1}$ ), ordered from the longest period for the lowest positive index to the smallest periods for higher indices. Both the trend and each of the cycles have their own amplitude determined by the initial conditions ( $k_{1}$ for the trend and $A_{i}=2\left|k_{i}\right|$ for each cycle), and each cycle has its own phase $\phi_{i}=\arg \left(2 k_{i}\right)$, determined by the initial conditions as well. We can estimate with an arbitrary precision the roots that give us the frequency and damping of each cycle, and which were already found by Frisch and his assistants at the Institute of Economic of Oslo. It is with the hindsight of this equation that we are able to rebuild Frisch's solution and discuss the different trajectories of his model.

Of course this is not the only approach to solve this model. However, it allows us to obtain this sum of components, which was in the original article of Frisch. Another approach would be to simulate the whole solution with a numerical integration of either (4) or the system of three equations (1)-(3). Frisch gave some elements in this direction, but due to the lack of computing powers in 1933 he was obviously limited in this regard. In addition, while this type of solution is useful to check the validity of our analytical solution and the level of approximation coming from the necessary truncation of the infinite series, it does not inform us in any way on the behaviour of the individual components. But such a simulation was carried out by Stefano Zambelli $(1992,2007)$, who noticed that simulating the model with Frisch's original parameters will give rise to a monotonous return to equilibrium instead of oscillations. This odd conclusion is due to the fact that Frisch was more interested in the trajectory of each cycle rather than the complete movement of his system (the addition of all components). In fact, Frisch believed that he was justified in treating the different elements of his solution separately, so that he gave different initial conditions to the "secular trend" and to the cycles. ${ }^{21}$ Frisch gave a starting value for the component (ii) that was below the equilibrium value of his system, so that it would grow as the model returned to its equilibrium. The superposition of cycles on this "secular trend"

21 For the different initial conditions, see Frisch (1933, pp. 18, 20 and 22). 
completed his model of growth and fluctuations. With the modern knowledge of a more complete theory of DDEs, we would not treat the components as separate; they all depend on the same initial conditions, and this leads to the unfortunate result that the system seems to go back monotonically to its equilibrium. However, unlike what Zambelli affirmed, it is possible to obtain the kind of fluctuations that Frisch described in his article after a slight change of parameters. This is important, because it shows that the conception of fluctuations and propagation advocated by Frisch was possible, and its deep influence on the econometric and macrodynamic movement was completely justified.

The following two figures present Frisch's original vision of trend and cycles, with a solution showing what we may call a "transitory growth", which he dubbed a "secular trend" (Frisch 1933, p. 18) in his original model. We suppose that the economy was artificially maintained at a lower level than its equilibrium level for some time (at least a time equal to $\epsilon$ ). In the following two figures, the parameters are fixed to $m=1, \lambda=0.3, r=1, s=2$ and $\mu=15$ :

\section{[INSERT FIGURE 1 HERE]}

Figure 1: Solution of $x(t), 1000$ components
[INSERT FIGURE 2 HERE]

Figure 2: Components one, two and three (trend and two cycles)

Figures 1 and 2 are the closest ones to the vision originally presented by Frisch in his article: there is a "secular trend" component that brings us toward the equilibrium level of the economy from the level where the economy was maintained, with about the same speed as in Frisch's original article. Then we have a primary cycle with a period of about 6.5 years, a secondary cycle with a period of about 3.2 years, and a third cycle (not represented in Figure 2) with a period of about 2.1 years, all values rather close to those in Frisch's article. The primary cycle is clearly seen when it is superposed to the trend component: there are several fluctuations before the new equilibrium level is reached, it has a relatively high magnitude (compared to the trend and other cyclical components), and finally it is less damped than the trend component. 
There is however one caveat compared to Frisch's original article: ${ }^{22}$ in order to obtain apparent cycles at the aggregate level, we had to decrease the damping of the system. In fact the return to equilibrium is much longer than in Frisch's original article. Is this a problem? We do not think that it necessarily is so: the propagation mechanism was only one part of the whole model, the second part being the impulse mechanism, which was used to explain the persistence of otherwise damped cycles. The fact that the propagation mechanism itself can explain a larger part of the persistence of cycles appears to be in line with Frisch's original objective of explaining the phenomena of sustained fluctuations in the business cycle. It is also true that we merely presented some examples of fluctuations, and that others could be found with different combinations of parameters, maybe quicker to return to equilibrium. One thing we can say is that throughout all the parameters we tested, we were unable to find a set of economically relevant parameters that would make the system unstable. This sheds an interesting light on a well-known fact about Frisch's approach to business cycles: that they are the manifestation of a stable process that would eventually reach a stationary level if left undisturbed. It is also a conclusion in line with his earlier work of 1927, where he had shown that the reinvestment cycles would be damped under very general conditions.

Something else which becomes apparent when we present the model like this is that his behavior does not look anything like a pendulum. While a pendulum, released from a position outside of equilibrium, would not swing back until the equilibrium position would be crossed, if we wanted to represent the fluctuations above with a pendulum we would have to make the pendulum oscillate on its way down toward the equilibrium position. In other words, instead of having an oscillation around the equilibrium, there would be oscillations around the path toward this equilibrium position. This image of the role of the secular trend in his model would be much closer to the reality depicted by the solutions than saying that the position of the equilibrium itself was moving; but of course it would be very difficult to construct a pendulum showing such a behavior. Because Frisch repeatedly used the pendulum metaphor in several of his papers, this may have hindered the recognition that his own economic model was not constructed in reference to a pendulum. The latter came only in the last section of his paper when Frisch presented how impulses interacted with a propagation mechanism, which was represented as a

22 We thank Pedro Garcia Duarte for calling our attention on this point. 
pendulum to simplify their interactions. However we can note that Frisch also tried to work out the effects of shocks on his economic model, as he mentioned in a 1934 letter to Tinbergen. ${ }^{23}$

\section{CONSTRUCTING ECONOMIC KNOWLEDGE FROM MATHEMATICAL DEBATES}

Frisch's approach to solving his model was one suited to his needs; he wanted a solution that would take the form of a sum of components, so he assumed that the solution would take this form and hoped for the best. Of course this was not a complete shot in the dark, as assuming an exponential function as a solution is a standard approach to solve differential equations.

Frisch also knew and took advantage of the fact that models mixing difference and differential equations gave rise to an infinity of components to decompose the solution of his models into a trend component and cyclical components featuring different periods, dampings, phases and amplitudes. This analytical approach mirrored the statistical approach of the 1920s: instead of estimating the cycles' features directly from the data, a theoretical model was built and (loosely) calibrated with the data, and it was solved such that the different components of the general solution would be apparent, and could be compared to the cycles periodicity already well studied. This meant that the model also took a life of its own: Frisch underlined in his article that in addition to the already known cycles of 8.5 and 3.5 years, he also found another cycle with a period of about two years, and he went a step further by hypothesizing that "if the various statistical production or monetary series that are now usually studied in connection with business cycles are scrutinized more thoroughly, ... then we shall probably discover evidence also of the tertiary cycle, i.e. a cycle of a little more than two years." (Frisch 1933, p. 20, original emphasis).

In this context, Frisch's perception of the output of his model becomes a lot more understandable. He viewed this output as symmetric to what was done on the decomposition of time series, although he pushed this idea a bit too far when he came to consider that the components he obtained could depend on different initial conditions. After Frisch, the idea of

23 "I have recently at our Institute had computed the shock maintained curves corresponding to the theoretical set-up in my 'Propagation Problems..."' (Letter from Frisch to Tinbergen, October 24th, 1934, RFA). 
considering independently the components of the model never really gained any traction. They were in fact the subject of some bewilderment from other economists; Roy Allen (1959, p. 302) called these higher terms spurious, "arising because of the rigid and unrealistic assumption of a fixed time-delay," and, reflecting on this period, Paul Samuelson acknowledged that he was stumped by their economic signification: "As a young student, what I found mystifying was the meaning of the infinite number of sinusoidal components of Frisch's more transcendental mixed differential-difference equation" (Samuelson 1974, p. 9).

The fact that Frisch was interested in this type of solution is underlined, in contrast, by other economists who kept only the first component and looked for parameters that would make it oscillate. This was in particular the approach developed by Jan Tinbergen, the first to take an interest in mixed equations. In his 1931 communication at the Lausanne meeting of the Econometric Society, he justified keeping only the solution with "minimum argument" by the fact that they are the most important from the economic point of view (Tinbergen 1933, pp. 4041). This was the same justification he offered in his "shipbuilding cycle" model, where he showed under which conditions the first solution would be longer than the lag period representing the construction time of ships. ${ }^{24}$

Kalecki, who used Tinbergen's 1931 solution in his model presented at the 1933 Leiden meeting of the Econometric Society, argued similarly that there was one solution that would have a period larger than the production lag of his model. ${ }^{25}$ Frisch, the editor of Econometrica at the time, left a note at this point of the report to argue that: "The uniqueness proof presented by Kalecki in his lecture did not seem convincing because his characteristic equation was not identical with Tinbergen's equation (for which the existence of a unique solution in the range considered is proved), but was a transformation of Tinbergen's" (Frisch in Marschak 1934, p. 194).

The discussions at Leiden on this matter seem to have shaken Kalecki's own belief in the justification of his solution. This about-face goes some length in explaining the delay in the

24 "Since, in general, the periods which are shorter than the lag period are of little interest we shall leave them out of our discussion." (Tinbergen, [1931] 1959, p. 11).

25 See for instance the report of the meeting by Marschak (1934, p. 194). 
publication of Kalecki's model, which waited for two years after its presentation in Leiden; in a letter sent to Frisch in 1934, Kalecki apologized for his lateness in sending the manuscript and indicated that it was due to the search of a satisfactory justification for the abandonment of the higher terms of the series: "I wished to argue better the dropping of further expressions of the general solution, as the fact of periods of fluctuations, which correspond to these expressions, being smaller than the gestation period $\theta$ does not appear to me a sufficient ground for it." (Kalecki to Frisch, March 29th, 1934, RFA). In his published paper, he advanced the hypothesis that the sum of other components would be very small and would not change the final solution, that they could in fact be made as small as an arbitrary value $\omega$ (Kalecki 1935, p. 334). ${ }^{26}$

However, this did not settle the other point raised by Frisch, that using Tinbergen's solution may not be warranted, as Kalecki's equation was slightly more complex than Tinbergen's. Kalecki asked Frisch whether he would be willing to look into the matter himself, to which Frisch answered positively. ${ }^{27}$ The note in the report, where Frisch pointed out that he had managed to derive Kalecki's result "by an independent method" which showed that Kalecki's result was correct, was one of the outputs of his effort. Another was the paper he prepared with one of his assistants at the Oslo Institute of Economics, Harald Holme. While this paper is often mentioned as a scathing critique of Kalecki's hypothesis on his choice of parameters, which allowed him to obtain self-sustained oscillations, it is interesting to note that the paper was in fact drawn in the framework of this debate about the economic significance of the higher terms of the solution. Throughout this paper, it is apparent that Frisch is still concerned with the problem of the superposition of exponential solutions with "major" and "minor" cycles, and the conditions under which such solutions would arise (see in particular table 2, in Frisch and Holme [1935, p. 233]), although the accent was put on the conditions of existence of the major cycle as he noticed that the minor cycles would have a period inferior to the lag (Frisch and Holme 1935, p. 239).

26 We can also note that this strategy of solving the model excluded the possibility of having both cycles and growth at the same time; because Kalecki retained only one component, it could either be a cycle or a trend (an exponential solution), but Kalecki was only interested at the time in the former. An earlier article by Assous et al. (2017) has already underlined that Kalecki's 1933-35 model could not generate both cycles and growth.

27 In addition to the March letter cited above, see also Frisch's answer, "At your request I shall look further into the question of the possibility of smaller gestation periods." (Frisch to Kalecki, April 5th, 1934, RFA), and Kalecki's reply accepting in advance his modifications (Kalecki to Frisch, April 12th, 1934, RFA). 
Those problems were also discussed between Frisch and Tinbergen in their professional correspondence. Frisch had asked Tinbergen to step in as associate editor of Econometrica in the spring of 1934, after the resignation of Frederick Mills, and their correspondence was consequently supplied with discussions on the papers to be published in the journal. ${ }^{28}$ Frisch mentioned Kalecki's request that he look into the problems discussed in Leiden, "namely the question of whether shorter cycles are possible as solutions of his system" (Frisch to Tinbergen, April 5th, 1934, RFA). Tinbergen, who had received Kalecki's paper, did not seem keen to spend more time on the problem. Frisch sent him his paper written with Holme a few months later, and asked him very earnestly his opinion on his findings. ${ }^{29}$ Tinbergen was of course very positive, and raised himself the problems of obtaining "realistic period (and realistic damping)," which he wanted to discuss in his own upcoming survey of business cycles (Tinbergen to Frisch, June 21st, 1934, RFA). This survey was another occasion of taking up the problems of mixed difference and differential equations, and Tinbergen presented his models alongside those of Frisch and Kalecki (Tinbergen 1935, p. 268 ff.).

The problem also surfaced during the fourth European meeting of the Econometric Society, in Stresa in 1934. While neither Tinbergen nor Frisch were present at that meeting, Luigi Amoroso, an early fellow of the Econometric Society, presented his own model of the economy based on mixed differential-difference equations. This was picked up by George Lutfalla, in charge of the meeting's report, who underlined that he had already drawn up a similar solution of such a model "concerning a theory of M. Ragnar Frisch" (Lutfalla 1935, p. 486) in his report of the Leiden meeting. In a similar manner as Frisch, Amoroso assumed that the solution of his model would be the result "of a composition of two evolutionary movements and one cyclical movement" (Lutfalla 1935, p. 486), that is, one cycle and one exponential representing the same kind of secular trend as in Frisch's model. But the way in which Amoroso arrived at this

28 Frisch asked him after Tinbergen wrote his first survey on economic theory for Econometrica and organized the 1933 Leiden meeting (see Frisch to Tinbergen, March 23rd, 1934, RFA). Tinbergen accepted gladly and waived any concerns about paying him a fee for his work: "as long as the nationalistic epidemy has not come over Holland and I shall have my present position, I have no need whatever of honorarium." (Tinbergen to Frisch, March 26th, 1934, RFA).

29 "Would you glance that through and at your earliest convenience let me have your opinion as to whether you think the essentials of this discussion are already contained in your previous papers, or whether you think this new paper contains the results in such a form that they are worth while publishing?" (Frisch to Tinbergen, June 6th, 1934, RFA). 
conclusion was rather different than that of Frisch: as can be seen in his publication based on this meeting (Amoroso 1935), he built a system of three mixed differential-difference equations, but completely neglected the lags when the time came of finding a solution, and reduced his system to three differential equations. Such a system having three roots, he searched for parameters that would give one real root (the exponential solution) and two complex conjugate roots giving a cycle (Amoroso 1935, p. 408-409).

The interest in those equations also reached England, where the Review of Economic Studies accepted in 1934 a contribution from J.B.S. Haldane, a biologist who presented a model hinged upon a production delay to represent the trade cycle; as he introduced rates of change in his model, he obtained equations that were very similar to those discussed here, and he remarked himself that "In 1933 Tinbergen published a paper on very similar lines ... His results are concordant with my own, though he is more concerned with the periods of oscillations than with their stability." (Haldane 1934, p. 195). Haldane was indeed more interested in the stability of his solutions than the problems of the period of oscillation and its relation to the production lag that was so important in the econometricians' approaches. But Tinbergen recognized the importance of the generality of his method in his survey, where he mentioned Haldane's paper in the section on "pure lag schemes" (Tinbergen 1935, p. 274).

Such problems were important enough in the small circle of econometricians interested in dynamic problems that they made their way to Australia, where Robert James and Maurice Belz examined the cases not considered by Frisch and Holme, who had also assumed that the parameters took certain values (James and Belz 1936). Belz had himself spent time in Oslo with Frisch in 1933, and was present at the Leiden meeting. ${ }^{30}$ Frisch accepted without difficulty the first paper which completed usefully his own paper with Holme, but was more reserved on the other articles sent by the two Australians (Erreygers 2019, p. 56). They nevertheless managed to publish two more papers, one presented by James at the 1937 Annecy meeting of the Econometric Society, where he introduced distributed lags in Kalecki's model (James and Belz 1938a), the other about "The Significance of the Characteristic Solutions of Mixed Difference and Differential Equations" (James and Belz 1938b). They recognized that "mixed difference and

30 Erreygers (2019) described the trajectories of Belz and James, and their relationship with Frisch. 
differential equations ... are beginning to assume considerable importance in econometrics, especially in connection with dynamical theories of the trade cycle." (James and Belz 1938b, p. 326). The methods they proposed were an impressive leap forward compared to what had been done already by Frisch, Tinbergen and others. In particular, they suggested using the solutions that would make the discontinuities in the solution disappear, the only "physically" significant for them (James and Belz 1938b, p. 328). They also introduced a method of solution based on the Fourier transform, that made clearly apparent the different component cycles and their dependence on the same initial conditions, something that Frisch had overlooked in order to focus on the separate cycles. They proposed to interpret the higher components that posed so much problems as the overtones or harmonics of a fundamental note (James and Belz 1938b, p. 331), drawing a justified analogy with physical processes, and they studied their stability, by trying to prove that if the first component is damped, all the other would also be damped (James and Belz 1938b, p. 330), which would justify discarding them because they would not impact the stability of the component with the largest period. But while we can interpret the different solutions arising, for instance, from a system of springs and masses (via the concept of normal modes), such an interpretation has never been given in economics, and the idea was largely abandoned.

Research continued after these works, but we end our story in the waning years of the $1930 \mathrm{~s}$, when the most important developments began to be published mostly in mathematical journals. What this development shows however, is that there were many ways to approach mixed differential-difference equations, and that the discussions around the best possible solutions were lively and fruitful. ${ }^{31}$ They also alimented the construction of macro-dynamic models, by centering the debates around some questions: how to show self-sustained oscillations, which periods were economically significant or how to explain growth and fluctuations in one model. The ideas feeding the debate participated actively in the construction of economic knowledge by deciphering the possible solutions of complex dynamic models, and their pioneering works formed at least some portion of the basis and justification for the works that came after the war to

31 The process of trying different hypotheses to solve a similar problem, proving or rejecting by counterexamples the assumptions on which they are based in the course of the debates is what Lakatos (1976) described as the logic of mathematical discovery. We thank an anonymous referee for pointing us to this reference to interpret and narrate the history and development of mathematical arguments. 
establish the mathematical tools that we used in this paper to present Frisch's solution. Indeed, the works of Frisch and Holme (1936) as well as Tinbergen ([1931] 1959) were cited by Bellman during the 1950s (e.g. Bellman and Danskin [1954]), and in his seminal work with Cooke (1963) they devoted a section to the solutions of Kalecki's 1933-35 model.

\section{CONCLUSION}

The rocking horse model was built over a number of years at the turn of the 1920s-1930s. From his previous work in capital theory, and his exchanges with American economists, Frisch progressively drew much of the economic content of his equations, but it was from his statistical work on the decomposition of time series that he found the kind of solution that he wanted from his model. Going back to his original model and his solution, we have shown that Frisch discussed the presence of cycles and a secular trend in his model. Concurrently and after his work, several other econometricians worked with similar differential-difference equations, but advocated a different approach to the solution of their models, which often did not leave any place for the presence of both growth and cycles. Clearly, the mathematical debates that followed formed an important part in the stabilization of macroeconomic dynamic models.

By staying close to Frisch's original model and paying attention to its specific form, we sought to give a new understanding of his original approach, and the kind of mathematical solutions he tried to build. To understand his ideas, we have eschewed the approach that consists in "reconstructing" a model with modern tools, and we remained very close to the type of solution advocated by the original author, both formally and historically. Thus we did not change his model, and we looked for a solution that would inform us on his properties as well as on the solution process that Frisch followed.

This approach, used in close relation with modern computing tools, helped us to gain an understanding of what interested the author. The active use of computer simulations, with the opportunities they offer to explore beyond the static page of the book, is a powerful tool to explore models and to discover their properties and the obstacles faced by the model builder; for instance in the case of DDEs, the problem of choosing the components to represent, or how to solve for the complete movement of the model arising from the superposition of all these 
components. In addition, this approach highlights the difficulties that forced the original modelbuilder to make specific choices, which often appear as a result of a compromise between what the economist wants to say and the tools at his disposal to say it.

\section{Acknowledgments}

Thanks are due to Michaël Assous for his advice on this paper, Pedro Garcia Duarte, Antonin Pottier, Ariane Dupont-Kieffer, Samuel Demeulemeester and two anonymous referees for their constructive comments, as well as to the participants to the workshop of PhD students in economics at Triangle, to the workshop of economists at Triangle, and to the workshop of the doctoral school of economics in Lyon for their questions and comments that helped improve this paper.

\section{ARCHIVES}

Ragnar Frisch Archives (RFA): some available at https://www.sv.uio.no/econ/english/about/factsand-figures/nobel-prize-winners/ragnar-frisch/ (consulted in March-April 2021) and personal copies

\section{REFERENCES}

Allen, R. G. D. 1959. Mathematical Economics. London: Macmillan.

Amoroso, Luigi. 1935. "La dynamique de la circulation." Econometrica 3(4): 400-410.

Andvig, Jens Christopher. 1981. "Ragnar Frisch and Business Cycle Research during the Interwar Years." History of Political Economy 13(4): 695-725.

Assous, Michaël, and Vincent Carret. 2021 (forthcoming). A history of early macroeconomics: How economists tackled the problem of economic instability. Springer.

Assous, Michaël, Amitava Dutt, Paul Fourchard, and Antonin Pottier. 2017. "(In)-Stability In Kalecki's Early Macroeconomics." Journal of the History of Economic Thought 39(1): 6987. 
Barnett, Vincent. 2006. "Chancing an Interpretation: Slutsky’s Random Cycles Revisited." European Journal of the History of Economic Thought 13(3): 411-32.

Bellman, Richard Ernest, and Kenneth L. Cooke. 1963. Differential-Difference Equations. Santa Monica: Rand Corporation.

Bellman, Richard Ernest, and John M. Danskin. 1954. A Survey of the Mathematical Theory of Time-Lag, Retarded Control, and Hereditary Processes. Santa Monica: Rand Corporation.

Bjerkholt, Olav. 1995. "Ragnar Frisch, Editor of Econometrica 1933-1954." Econometrica 63(4): 755-65.

Bjerkholt, Olav. 2007. "Ragnar Frisch’s Business Cycle Approach: The Genesis of the Propagation and Impulse Model." European Journal of the History of Economic Thought 14(3): 449-86.

Bjerkholt, Olav, and Ariane Dupont-Kieffer. 2010. "Ragnar Frisch's Conception of Econometrics." History of Political Economy 42(1): 21-73.

Bjerkholt, Olav, and Duo Qin. 2010. “Editors' Introduction. Teaching Econometrics as a Science: The Yale Lectures of Ragnar Frisch.” pp. 1-28 in A Dynamic Approach to Economic Theory: The Yale Lectures of Ragnar Frisch, edited by O. Bjerkholt and D. Qin. London: Routledge.

Boianovsky, Mauro, and Hans-Michael Trautwein. 2007. "Johan Åkerman vs. Ragnar Frisch on Quantitative Business Cycle Analysis." European Journal of the History of Economic Thought 14(3): 487-517.

Boumans, Marcel. 1999. "Built-in Justification." In M. S. Morgan and M. Morrison, ed., Models as Mediators: Perspectives on Natural and Social Science. New York: Cambridge University Press, pp. 66-96.

Cargill, Thomas F. 1974. "Early Applications of Spectral Methods to Economic Time Series." History of Political Economy 6(1): 1-16. 
Chipman, John S. 1998. "The Contributions of Ragnar Frisch to Economics and Econometrics." pp. 58-108 in Econometrics and Economic Theory in the 20th Century, edited by S. Strom. Cambridge: Cambridge University Press.

Clark, J. M. 1932. "Capital Production and Consumer-Taking: A Further Word." Journal of Political Economy 40(5): 691-93.

Davis, Harold T. 1941. The Analysis of Economic Time Series. Bloomington: Principia Press.

Duarte, Pedro Garcia, and Kevin D. Hoover. 2012. "Observing Shocks." History of Political Economy 44(suppl): 226-249.

Dupont-Kieffer, Ariane. 2003. "Ragnar Frisch et l'économétrie : l'invention de modèles et d'instruments à des fins normatives." PhD diss., Université Paris 1 Panthéon-Sorbonne, Paris.

Dupont-Kieffer, Ariane. 2012a. "Lindahl and Frisch: Linking Macroeconomics and National Accounting in the Interwar Years for Economic Policies and Planning." Journal of Economic \& Social Measurement 37(1/2): 145-74.

Dupont-Kieffer, Ariane. 2012b. "The Accelerator Principle at the Core of Frisch's 1933 Rocking Horse Model: Tracing Back the Influences: American Institutionalism and Norwegian Investment Cycles Theories." Journal of the History of Economic Thought 34(4): 447-73.

Erreygers, Guido. 2019. "On the Origins of Econometrics in Australia. The Contributions of Maurice Belz and Robert W. James." History of Economics Review 74(1): 46-63.

Fourier, Jean Baptiste Joseph. 1822. Théorie analytique de la chaleur. Paris: Firmin Didot, père et fils.

Frisch, Ragnar. 1927. "Sammenhengen Mellem Primærinvestering Og Reinvestering." Statsøkonomisk Tidsskrift 41: 117-52.

Frisch, Ragnar. 1928. "Changing Harmonics and Other General Types of Components in Empirical Series." Scandinavian Actuarial Journal 1928(1): 220-236. 
Frisch, Ragnar. 1931a. "A Method of Decomposing an Empirical Series into Its Cyclical and Progressive Components." Journal of the American Statistical Association 26(173S): 73-78.

Frisch, Ragnar. 1931b. "The Interrelation Between Capital Production and Consumer-Taking." Journal of Political Economy 39(5): 646-54.

Frisch, Ragnar. 1933. "Propagation Problems and Impulse Problems in Dynamic Economics." reprinted from Economic Essays in Honour of Gustav Cassel. Oslo: Universitetets Okonomiske Institutt.

Frisch, Ragnar, and Harald Holme. 1935. "The Characteristic Solutions of a Mixed Difference and Differential Equation Occurring in Economic Dynamics." Econometrica 3(2): 225-39.

Haldane, J. B. S. 1934. "A Contribution to the Theory of Price Fluctuations." Review of Economic Studies 1(3): 186-95.

James, R. W., and M. H. Belz. 1936. "On a Mixed Difference and Differential Equation." Econometrica 4(2): 157-60.

James, R. W., and M. H. Belz. 1938a. "The Influence of Distributed Lags on Kalecki's Theory of the Trade Cycle." Econometrica 6(2): 159-62.

James, Robert W., and Maurice H. Belz. 1938b. "The Significance of the Characteristic Solutions of Mixed Difference and Differential Equations." Econometrica 6(4): 326-43.

Kalecki, Michał. 1935. "A Macrodynamic Theory of Business Cycles." Econometrica 3(3): 32744.

Lakatos, Imre. 1976. Proofs and Refutations: The Logic of Mathematical Discovery. Cambridge University Press.

Le Gall, Philippe. 1993. "Les Contributions de Kalecki et Frisch à La Macrodynamique Du Cycle et La Naissance de l'économétrie / The Contributions of Kalecki and Frisch to Business Cycle Macrodynamics and the Birth of Econometrics." Revue d'économie Politique 103(4): 551-78. 
Le Gall, Philippe. 1999. "A World Ruled by Venus: On Henry L. Moore’s Transfer of Periodogram Analysis from Physics to Economics." History of Political Economy 31(4): $723-52$.

Legrand, Muriel Dal-Pont, and Harald Hagemann. 2019. Impulses and Propagation Mechanisms in Equilibrium Business Cycles Theories: From Interwar Debates to DSGE "Consensus." 2019-01. Groupe de REcherche en Droit, Economie, Gestion (GREDEG CNRS), University of Nice Sophia Antipolis.

Louçã, Francisco. 2001. "Intriguing Pendula: Founding Metaphors In The Analysis Of Economic Fluctuations." Cambridge Journal of Economics 25(1): 25-55.

Louçã, Francisco. 2007. The Years of High Econometrics: A Short History of the Generation That Reinvented Economics. London: Routledge.

Lucas, Robert E., and Thomas J. Sargent. 1979. "After Keynesian Macroeconomics." Federal Reserve Bank of Minneapolis Quarterly Review 3(2): 1-16.

Lutfalla, Georges. 1934. “Compte Rendu de La III e Réunion Européenne de La Société Internationale d'Econométrie. (Leyde, 30 Septembre-3 Octobre 1933.)." Revue d'économie Politique 48(2): 414-42.

Marschak, Jakob 1934. "The Meetings of the Econometric Society in Leyden, SeptemberOctober, 1933." Econometrica 2(2): 187-203.

Moore, Henry L. 1921. "Generating Cycles Reflected in a Century of Prices." Quarterly Journal of Economics 35(4): 503-26.

Morgan, Mary S. 1990. The History of Econometric Ideas. Cambridge: Cambridge University Press.

Prescott, Edward C. 2006. "The Transformation of Macroeconomic Policy and Research." The American Economist 50(1): 3-20.

Samuelson, P. A. 1974. "Remembrances of Frisch." European Economic Review 5(1): 7-23. 
Slutzky, Eugen. 1937. "The Summation of Random Causes as the Source of Cyclic Processes." Econometrica 5(2): 105-46.

Tinbergen, Jan. 1933. "L'utilisation des équations fonctionnelles et des nombres complexes dans les recherches économiques." Econometrica 1(1): 36-51.

Tinbergen, Jan. 1935. "Annual Survey: Suggestions on Quantitative Business Cycle Theory." Econometrica 3(3): 241-308.

Tinbergen, Jan. [1931] 1959. "A Shipbuilding Cycle." in L. H. Klaassen, L. M. Koyck, and H. J. Witteveen, ed., Jan Tinbergen Selected Papers. North-Holland Publishing Company, pp. 114.

Turner, Paul, and Justine Wood. 2020. "New Perspectives on Henry Ludwell Moore's Use of Harmonic Analysis." Journal of the History of Economic Thought 42(4): 507-20.

Vianna Franco, Marco P., Leonardo Costa Ribeiro, and Eduardo da Motta e Albuquerque. "Beyond Random Causes: Harmonic Analysis of Business Cycles at the Moscow Conjuncture Institute." Journal of the History of Economic Thought (forthcoming).

Wiener, Norbert. 1930. “Generalized Harmonic Analysis.” Acta Mathematica 55(1): 117-258.

Zambelli, Stefano. 1992. "The Wooden Horse That Wouldn't Rock: Reconsidering Frisch." pp. 27-56 in Nonlinearities, Disequilibria and Simulation: Proceedings of the Arne Ryde Symposium on Quantitative Methods in the Stabilization of Macrodynamic Systems Essays in Honour of Björn Thalberg, edited by K. Velupillai. London: Palgrave Macmillan UK.

Zambelli, Stefano. 2007. "A Rocking Horse That Never Rocked: Frisch's 'Propagation Problems and Impulse Problems." History of Political Economy 39(1): 145-66. 